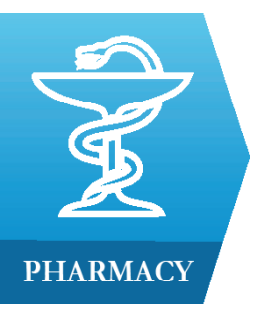

1) Department of Pharmaceutical Chemistry, Pharmacy Division, Faculty of Medicine, "Hasan Prishtina" University, Prishtina, Republic of Kosovo

2) Department of Clinical Pharmacy and Biopharmacy, Pharmacy Division, Faculty of Medicine, "Hasan Prishtina" University, Prishtina, Republic of Kosovo

DOI: $10.15386 / \mathrm{mpr}-1756$

Manuscript received: 02.06.2020

Received in revised form: 22.06 .2020

Accepted: 30.06.2020

Address for correspondence:

rozafa.koliqi@uni-pr.edu

This work is licensed under a Creative Commons Attribution-NonCommercialNoDerivatives 4.0 International License

\title{
A review of the current understanding of nanoparticles protein corona composition
}

\author{
Pranvera Breznica ${ }^{1}$, Rozafa Koliqi ${ }^{2}$, Arlinda Daka ${ }^{2}$
}

\begin{abstract}
Upon entering into the biological environments, the surface of the nanoparticles is immediately coated with proteins and form the so-called a protein corona due to which a nanoparticle changes its "synthetic" identity to a new "biological" identity. Different types of nanoparticles have different protein binding profiles, which is why they have different protein corona composition and therefore it cannot be said that there is a universal protein corona. The composition and amount of protein in the corona depends on the physical and chemical characteristics of the nanoparticles, the type of biological medium and the exposure time. Protein corona increases the diameter but also changes the composition of the surface of the nanoparticles and these changes affect biodistribution, efficacy, and toxicity of the nanoparticles.
\end{abstract}

Keywords: nanoparticles, protein corona, nano-biointerface

\section{Introduction}

Our bodies are well adapted to protect us from different foreign materials and have developed clearance mechanisms which that are extremely efficient in removing intravenous administered colloidal carriers. During intravenous administration, nanoparticles first come into contact with plasma proteins, but in subsequent stages are eventually distributed to certain tissues or cells [13]. Therefore, controlling properties like hydrodynamic radius, morphology, surface charge, surface chemistry, hydrophilicity and hydrophobicity known to influence reticuloendothelial system (RES) recognition, as well as to predict nanoparticle (NP) bioreactivity is crucial throughout the drug delivery system design.

\section{Physico-chemical properties of nanoparticles}

Particle size, total surface area and its curvature are factors that affect proteins binding. The authors suggest that in addition to surface, the curvature of the smaller particles also plays a role in the greater affinity for protein adsorbtion.
The affinity of proteins for nanoparticles is different for particles of different sizes, which is why there are qualitative and quantitative differences in their protein corona content $[4,5]$. Lynch and colleagues examined the effect of particle size and their surface area on protein adsorbtion. The results showed that as the particle size of N-isopropylacrylamide/N-tertbutylacrylamide nanoparticles (NIPAM/ BAM) increased from 70 to $700 \mathrm{~nm}$, the amount of absorbed protein decreased as a result of the reduced contact area [6]. On the other hand, there are conflicting data showing that the adsorbtion of $110 \mathrm{~nm}$ silver nanoparticles is twice as high as that of $20 \mathrm{~nm}$ particles [7]. Reverse proportional dependence has also been shown in adsorbtion of mouse serum proteins on gold nanoparticles with diameters of 5, 15, and $80 \mathrm{~nm}$ [8].

Usually, the intensity of protein adsorbtionis increased by increasing the surface charge, so for example, it is well known that positively charged nanoparticles are quickly recognized and taken from RES structures, which is why they are almost immediately distributed in the liver and spleen, and thus limiting 
their use. Gessner noted differences in protein adsorbtion in particles with different surface charges, where positively charged polystyrene nanoparticles absorb proteins with $\mathrm{pI}$ $<5.5$, such as albumin, and negatively charged nanoparticles absorb proteins with $\mathrm{pI}>5.5$, such as $\operatorname{IgG}$ [9]. Proteins that are absorbed on charged surfaces can be denatured. In one study is found that proteins absorbed by gold particles with positively and negatively charged ligands denatured (losing secondary and tertiary structure), while proteins absorbed by gold nanoparticles with non-charged ligands retain their natural structure [10].

The correlation between nanoparticle hydrophobicity and protein adsorbtion is also important. Hydrophobicity has been shown to not only affect the amount of protein absorbed, but also the qualitative composition of the protein corona $[11,12]$. It is well known in the literature that hydrophobic surfaces have a greater affinity for protein adsorbtion, are more rapidly oxidized, and have a greater tendency to denature adsorbed proteins than hydrophilic surfaces [13]. This is probably due to the number of so-called protein binding sites or sites where polymer chains form clusters that act as protein binding sites. There are a number of comparative studies confirming differences in adsorbtion capacity as well as the qualitative and quantitative composition between hydrophilic and hydrophobic surfaces $[13,14]$.

In a comparative study of protein adsorption of less hydrophobic nanoparticles of copolymer NIPAM/BAM 85:15 and more hydrophobic nanoparticles of copolymer NIPAM/BAM 50:50, it was found that a higher number of apolipoproteins (AI, AII, AIV and E), fibrinogen etc., have been absorbed by more hydrophobic nanoparticles, while less hydrophobic nanoparticles almost do not absorb proteins with the exception of albumin. It has also been shown that apolipoprotein A-I has 50 times more the affinity for NIPAM/BAM 50:50 copolymer nanoparticles compared to those prepared from NIPAM / BAM 65:55 copolymer, which clearly indicates that proteins have a greater affinity for more hydrophobic surfaces [15].

Generally, modification of the surface of NPs with a hydrophilic layeris known to reduce opsonisation and enhance blood circulation time of NP's by providing "stealth effect", i.e., making the NP invisible to immune cell recognition. Many publications described that superior results obtained with poly(ethylene glycol) (PEG)-based coating of NP attributed to its hydrophilicity, which remarkably extend circulation time of nanoparticles in blood [16-18].

\section{Analytical methods for characterizing the protein corona}

To fully understand the impact of the protein corona and its importance in the targeted therapeutic systems, it is necessary to determine which proteins are adsorbed on the surface of a particle, their kinetics of adsorption, affinity, and stoichiometry of adsorbtion and desorption [19]. There are several techniques for separating and identifying plasma proteins that are absorbed on the surface of nanoparticles such as centrifugation, gel filtration, magnetic separation [20]. Although all of these techniques show similar protein adsorption profiles, experimental data suggest that each technique has certain advantages and disadvantages. There are several methods for determining the quantitative composition of adsorbed proteins on the surface of nanoparticles such as: equilibrium dialysis, ultracentrifugation, affinity chromatography, protein microelements, gel filtration, HPLC and others [21]. However, some of these methods have limited use in certain types of nanoparticles in terms of diameter and some specific chemical characteristics. For example, certain nanoparticles have intrinsic properties in terms of light adsorption or fluorescence that can interfere with certain protein microelements. Because crowns of protein are present in the corona, it is necessary for each protein to be separated and identified, and the most widely used method is 2D polyacrylamide electrophoresis. Thus, in order to identify specific proteins, it is necessary to compare the $2 \mathrm{D}$ gel with a known protein database identified by $2 \mathrm{D}$ electrophoresis [22,23].

It is necessary to develop analytical methods with standardized protocols for testing and characterizing the interactions between nanoparticles and biomolecules, which will allow researchers to understand the mechanical basis of the possible biological activity of these complexes in order to predict the reliability of nanoparticles biological application. An overview of several such methods is given in a Table I along with the advantages and disadvantages of each [24,25].

So far, there is no gold standard for evaluating the interaction of proteins/biomolecules with nanoparticles, so it is recommended to combine several different characterization methods as a strategy that compensates for the shortcomings and limitations of individual methods. It is clear that determining the qualitative and quantitative profile of the protein corona is the primary critical step in evaluating nanosystems in order to understand their impact on living organisms. However, although such information is key to the subsequent interpretation and prediction of potentially biologically effective protein corona, this data should be supplemented by complex biological tests.

At present, cellular models of protein corona nanoparticles are very rarely used. In addition, due to the lack of standardized methods, comparing the results obtained in different laboratories is practically impossible, and sometimes leads to contradictory conclusions [26,27]. In order to overcome this problem, screening experimental models ((high-throughput screening (HTS) / high-content screening (HCS)) should be used. This would be achieved by using technological knowledge obtained in the development of drugs, as well as in the evaluation of their toxicity in industrial and academic laboratories over the last ten years [28-30]. Screening models for cell lines based on cell responses along with certain chemicals are now being used to predict responses to nanoparticles. 
Table I. Analytical methods for protein corona evaluation.

\begin{tabular}{c|c|c} 
Methods & Advantages & Disadvantages \\
\hline \multicolumn{2}{|c|}{ Spectroscopic methods } \\
\hline \multicolumn{2}{|c|}{ Spestic } \\
\hline
\end{tabular}

\begin{abstract}
UV / Visible spectroscopy

Inexpensive; fast; simple; a small amount of sample
\end{abstract}

\section{Fluorescence spectroscopy \\ Fourier-transform infrared spectroscopy}

Surface-enhanced Raman spectroscopy (SERS)

Nuclear magnetic resonance spectroscopy (NMR)

Surface plasmon resonance spectroscopy (SPR)
Low particle concentration; hydrodynamic radius can be calculated with great precision under nanometer dimensions

Inexpensive; functional groups are easily identified; sensitive to protein conformation; not limited in size and material

Can be used for both solid and liquid materials; no need to prepare a sample; fast; spectra can be obtained using a small sample volume; no water interference

Provides information on structural changes in highresolution proteins; quantitative and qualitative analysis; organic and inorganic materials; can be easily adjusted for proper application

The conformity of immobilized proteins and the kinetics of binding to the surface of nanoparticles are examined
The solution ( $\mathrm{pH}$, electrolyte, presence of interfering substances) may affect the adsorbtion spectrum; the effective frequency range must be controlled; it is difficult to obtain quantitative results; should be used in combination with complementary spectroscopic and structural examination

Fluorescent-marked particles are required; sensitive to the presence of aggregates; can only be used for samples with good colloidal stability

Characterization in complex media is not possible; durable; the sample may be destroyed when preparing a sample for analysis

Weak Raman effect; sensitive and highly optimized instrument; cannot be used for metals and alloys; impurities can override the perspective; laser sample heating can destroy the sample

Long lasting; expensive; experimental and theoretical expertise are required

System detection limit

\section{Light scattering techniques}

\section{Dynamic light scattering} Electrophoretic
light scattering
Method for determining the particle size distribution; fast and accurate method

Surface voltage measurement method in different biological environments
All particles present in the biological sample have a share in light scattering; challenge is the characterization of a heterogeneous biological sample; the diameter is usually larger than that measured by an electron microscope; not suitable for polydisperse samples

Nanoparticles should be monodisperse; $\mathrm{pH}$ dependent surface voltage and aggregation
Liquid Chromatography High resolution; unique in determining protein - Mass Spectroscopy (LC-MS)

Gel electrophoresis (1D/2D) identity; quantitative and qualitative analysis; less possibility of user bias

Separation of protein mixtures; suitable for quantitative and qualitative analysis; easy to perform; inexpensive; widely used; possible comparison between different laboratories; reproducible
Long lasting; expensive; experimental and theoretical expertise are required

Low detection limit; it is necessary to separate the proteins from the nanoparticles; use of strong buffers; laborious performance; provides only partial insight into the protein corona; propensity to form artifacts
Although conventional two-dimensional (2D) cellular monocultures are ideal for future HCS/HTS approaches and have already provided significant information regarding corona and biological response structure (CoroNanoSARs) and/or toxicity pathways (PoTs), the relevance of the results obtained must be confirmed by the use of cellular models that better simulate in vivo conditions. In this regard, efforts are being made to develop complex three-dimensional (3D) cellular systems that can better mimic the functions of a given tissue. Compared to 2D cell cultures, 3D models can better simulate signaling pathways and the response induced by the presence of nanoparticles [31-33]. Although 3D cell models provide certain functions such as communication between intercellular and intracranial pathway cell regulation, as well as inter and intracellular transport of nanosystems that cannot be achieved in monocultures, we are still far from complete mimicry of biological tissues [34,35]. 
In addition to $2 \mathrm{D} / 3 \mathrm{D}$ cellular systems, technological development in the field of nanotechnology allows the design of a "chip organ" system, which does not lead onestep closer to achieving complete imitation of a particular tissue. Despite all the challenges, "chip systems" have great potential to reduce the use of expensive and longterm experiments on experimental animals and to speed up the process of evaluating the safety of nanomaterials. Despite their great potential, such tools have not yet been used to investigate the impact of biomolecular corona $[36,37]$.

However, in the end, in vivo experiments will be needed to confirm the corona's impact on biological activity as well as on the toxicity mechanisms that depend on the protein corona. Different animal models are available to examine the impact of the biomolecular corona on the surface of the nanoparticles on human health [38].

Namely, recent research has also successfully applied HTS/HCS approaches using entire animals, such as zebra fish $[39,40]$. However, so far there has been a lack of comprehensive research reports focusing specifically on the biomolecular corona. It is clear that researchers face a variety of experimental and analytical challenges in researching not only the "simple" endpoints, such as vitality, but also analyzing the fate and biotransformation of nanoparticles that are thought to depend on the corona.

\section{The composition of protein corona}

There is no consensus in the literature on the advantages and disadvantages of protein adsorbtion. For example, protein adsorbtion to the carrier surface is beneficial if it has to cross the blood-brain barrier. One study found that covalent binding of ApoE3, ApoA-I, or ApoB-100 to albumin nanoparticles significantly improved the transport of loperamide through the blood-brain barrier compare to the drug itself or non-functional nanoparticles $[41,42]$. Similar results have been obtained with other drugs aimed at brain tissue, such as methoxorubicin, using polysorbate 80-coated polybutylcyanoacrylate (PBCA) nanoparticles coated with polysorbate- 80 and ApoE [43].

The composition of the protein corona is very complex, variable and very dependent on the initial biological environment that comes in contact with the nanoparticles, which indicates the possibility of the existence of memory on exposure. Certain components of the so-called protein corona such as Opsonins (IgG,complement and many others) may accelerate the RES uptake of coated nanoparticles [44,45]. On the other hand, there are so-called proteins dysopsonins, such as albumin, which, if coated with particles, prevent the activation of the complement, thus prolonging the circulation time and reducing toxicity [46,47]. The rate of adsorbtion and desorption for each protein determines the retention time in the corona and the way it interacts with the nanoparticle surface. Prolonged or irreversible protein binding in nanoparticle leads to the formation of a "solid corona". Behind the solid corona lies the soft corona, which is a layer of proteins that have a high rate of adsorbtion/ desorption due to which their binding to the corona is reversible. Thus, the composition of the protein corona is dynamic and the proteins with high plasma concentrations and adsorbtion constants will be in the initial maturation of the corona.

This competitive process of protein adsorbtion, which depends on protein concentration, affinity, and incubation time, is known as the Vroman effect [48]. Although there are certain proteins that are specific to certain nanoparticles and their composition in the protein corona depends on the characteristics of the nanoparticle, albumin, IgG, fibrinogen, and apolipoprotein are the proteins identified in almost all protein corona analyzes [49]. According to Carvedal and colleagues, this phenomenon is due to the high concentration of these proteins in the blood.

The composition of the protein corona at any time will depend on the concentration and kinetic properties of the plasma proteins, which is why it is important to know the dynamics of corona protein exchange, which will determine the role of the protein corona in the overall biological profile of nanoparticle [48]. Several trials of unexplained nanoparticles have shown that in biological media, solid corona proteins change very slowly, most of them over a period of several hours, while those of soft corona change very rapidly, within a few seconds. This time discrepancy points to the fact that the key factor in the biological behavior of nanoparticles lies in the interface of the solid and soft protein corona. A kinetic analysis of the protein corona of solid nanoparticles showed that the albumin was initially bound to the nanoparticles and then replaced by fibrinogen, after which fibrinogen was replaced by apolipoproteins. High plasma concentrations of apolipoproteinshave been shown to be able to replace fibrinogen within seconds [50]. Another study showed the kinetics of protein adsorbtion of lecithin-coated polystyrene nanoparticles. The results showed qualitative and quantitative changes in the protein corona. Namely, the corona content of $\mathrm{C} 3, \mathrm{IgG}$ and $\mathrm{ApoE}$ increased during the test period (360min), while the albumin content remained unchanged [51].

As mentioned above, serum proteins have a dynamic surface adsorbtion profile, with abundant proteins (such as albumin and fibrinogen) usually being the first to be absorbed on the surface, after which they are gradually altered by other proteins that have a higher affinity for surface adsorbtion (Vorman theory). The sequence of adsorbtion of plasma proteins by carbon nanotubes (SWCNT) is as follows: fibrinogen, immunoglobulins, transferrin, and albumin. It should be noted that there are many studies that suggest that the adsorption of plasma 
proteins at the surface of nanoparticles does not always follow Wroman's theory, such as the plasma protein adsorption profile for ultra-small super paramagnetic iron oxide nanoparticles (SPION). This is why it should be noted that the exchange of proteins in the protein corona over a period of time is not a universal rule that should be accepted in all cases and for all types of nanoparticles [52,53].

It should also be noted that the surface area and flexibility of nanoparticles, as well as the chemical properties of each absorbed protein, play an important role in modifying the secondary structure of proteins, thus affecting the overall bioreactivity of nanoparticles. Unlike the planar surface, the curved surface of nanoparticles provides additional flexibility as well as an increased surface area for protein molecule adsorbtion [54]. In addition, the curved surface of the nanoparticles may also affect the secondary structure of the protein, and in some cases irreversible changes may occur [55].

For example, gold nanoparticles have been shown to affect the conformational changes of the secondary structure of bovine serum albumin (BSA) and thus dependence on concentration [56], while no changes were observed when BSA was absorbed on the surface of carbon C60 fullerenes, nanoparticles [57]. Irreversible conformational changes in the secondary structure of transferrin have been observed in interaction with SPION [58]. Such conformational changes, which depend on the type of nanoparticles, can affect protein interactions, cell signaling, and DNA transcription.

Also, the surface of the nanoparticles may induce abnormal protein binding, whereby new conformational epitopes may form that will affect the functionality of the bound proteins, for example, leading to an undesirable immune response. Deng and colleagues investigated this problem when evaluating gold nanoparticles conjugated to poly (acrylic acid) and absorbed plasma fibrinogen. Fibrinogen excretion was induced immediately after adsorption of nanoparticles, and as a result, the TPH-1 cell receptor Mac-1 was activated, causing the release of inflammatory cytokines via the NF- $\kappa \beta$ pathway [59].

These results suggest that in addition to the mechanism of association of proteins with nanoparticles, there is another significant area that is insufficiently explained, such as the interaction of proteins with the surface of particles. Although hydrophobic / hydrophilic and electrostatic interactions are known to play a major role, no one describes these interactions in detail. Detailed knowledge of these interactions can lead to a better understanding of the factors that influence the kinetics of protein binding. Therefore there is a need to improve analytical procedures and techniques in order to fully explain the complex processes of interaction between proteins and nanoparticles.

\section{The impact of protein corona on the in vivo properties of NP}

Basically, all interactions between nanoparticles that have a protein corona and structures in the biological environment are driven by physical forces, common to all molecular systems, such as Van der Waals, electrostatic, and others [60]. However, it would be useful to make a classification as to whether these interactions involve nonspecific physical interaction [61] or specific biological recognition [62]. Therefore, it is very important to determine the impact of biomolecular corona on the uptake of nanoparticles by cells, their efficacy and toxicity.

The uptake of nanoparticles by cells may be either inhibited as a result of a change in the structure of the attenuated proteins, or facilitated by the detachment of the attenuated proteins, allowing interaction with the receptors on the cell membrane. This is especially important when specifically binding of physiologically active protein on the surface of nanoparticles. Several in vitro studies evaluating the effect of serum proteins on non-specific cellular uptake of nanoparticles have shown that the degree of internalization of nanoparticles largely depends on the presence of the protein corona $[63,64]$. Wang and colleagues analyzed the difference in cellular uptake of two different types of gold nanoparticles coated with peptides in Dulbecco's modified Eagle medium (DMEM), with and without the presence of $10 \%$ fetal bovine serum (FBS), and noted a higher degree of uptake when serum was not present in the medium [63]. Patel and colleagues have also published similar results for gold nanoparticles (GNP) coated with oligonucleotides, where nanoparticle uptake increased by $150 \%$ when a serum-free medium was used [64]. In addition, the formation of protein corona has been shown to significantly reduce the uptake of FePt nanoparticles by Hela cells compared with coronafree nanoparticles $[10,65]$. It is also thought that the total amount of protein absorbed in the corona has an effect on the degree of uptake. For example, gold nanoparticles with diameters of 15,40 , and $80 \mathrm{~nm}$ have been shown to behave differently in the two examined media, DMEM and Roswell Park Memorial Institutemedium (RPMI) with $10 \%$ FBS, with a thicker corona being formed in DMEM. Although the growth rate of Hela cells was the same in both media, a lower degree of nanoparticle uptake was observed in DMEM [66]. Therefore, it can be concluded that the formation of biomolecular corona leads to a decrease in the adhesion of nanoparticles to the cell membrane, which reduces their toxicity. Several studies have been published that suggest that the protein corona promotes the specific uptake of nanoparticles by cells. Dutta and colleagues have shown that the albumin atrophied on the surface of single-walled carbon nanotubes (SWCNT) is responsible for inducing the anti-inflammatory pathway in RAW macrophages, emphasizing that the identity of attraction 
proteins can be determined by bioreactivity [67]. It has also been shown that the attraction of the SR-A lung protein to the surface of magnetic nanoparticles increases the rate of macrophage uptake compered to BSA-coated nanoparticles [68]. Caracciolo et al. reported that nanoparticles, with the help of the formed protein corona, could be targeted at specific cells if there was a specific functional protein among the proteins whose recipe was overexpressed on the surface of the diseased cells [69].While specific targeting can sometimes be enabled due to the formation of a protein corona, the degree of nonspecific targeting is reduced in the presence of a protein corona.

As a result of lower cell uptake, the presence of a protein corona reduces the toxicity of the nanomaterial. This was announced by Maiorano, who conducted a whole set of tests to test the toxicity (activity of mitochondria, apoptosis and DNA fragmentation) of gold nanoparticles diluted with DMEM and RPMI, and found that a smaller corona to a surface area of gold nanoparticles leads to higher degree of uptake as well as greater toxicity $[66,70]$. Similar results have been reported for carbon nanotubes, graphene oxide nanoparticles, and polymer nanoparticles examined using different cell lines [71-73].

However, toxicity may occur as a result of modification of the proteins on the surface of the nanoparticles which may lead to a change in their biological activity, as observed for catapsin $\mathrm{B}$, which in the presence of gold nanoparticles is detached or leads to disruption of cellular machinery, recognition of immunoglobulins, and subsequent activation of macrophages and inflammation [74].

The literature suggests that corona has the role of a sponge with a larger capacity to incorporate the active substance compared to covalent coagulation-based strategies, so this feature can be used to incorporate small molecules with therapeutic effect (ex. doxorubicin) in order to increase the toxicity against cancer cells [75].

It should also be noted that the presence of protein corona on the surface of lignocellulose-functional nanoparticles (antibodies, aptamers, etc.) has an impact on their targeting ability. This has been described by Mirshafiee and Coll, who in quantifying the effectiveness of acid-targeted bicyclocanin-silicate nanoparticle (BCN-NP) targeting in the presence of 10 or $100 \%$ FBS observed that targeting efficiency was $94 \%$ and $99 \%$ lower in comparison with BCN-NP without protein corona [76]. Similar results were obtained by examining silicon nanoparticles functionalized with transferrin, where it wasobserved that nanoparticles lost their ability to target at elevated serum concentrations [77]. These data suggest that just adding a ligand to the surface of the nanoparticles is not enough to ensure recognition and binding to the appropriate receptor, because the protein corona can act as a barrier and prevent the nanoparticles from trying to destroy the "real" cells. Dai and colleagues suggest strategies to overcome this obstacle by using polyethylene glycol with appropriate chain lengths, which can improve the selective targeting of nanoparticles in the presence of serum [78].

\section{Conclusion}

Based on the above, it can be concluded that physico-chemical characteristics play an important role in the biodistribution of nanoparticles. Nevertheless, there are gaps in understanding the mechanisms of how these factors affect protein adsorbtion and how the protein corona affects biodistribution, biocompatibility and the therapeutic efficiency of the nanoparticles.

The protein binding mechanism is not entirely clear, however, it is known that the qualitative and quantitative composition of the protein corona plays an important role in the biodistribution of nanoparticles. Moreover, the isolation of nanoparticles from various organs, such as the liver, lungs, or tumor tissue under experimental conditions when preserving the corona, requires the development of new extraction protocols, as well as new advanced techniques. As mentioned above, the information obtained starting from the analysis of the protein corona using HTS 2D/3D in vitro models combined with bioinformatics predictions, can enable rational design and performance of animal experiments, as well as the development of specific tools according to the mechanism being investigated.

\section{References}

1. Karmali PP, Simberg D. Interactions of nanoparticles with plasma proteins: implication on clearance and toxicity of drug delivery systems. ExpertOpinDrug Deliv. 2011;8:343357.

2. Saptarshi SR, Duschl A, Lopata AL. Interaction of nanoparticles with proteins: relation to bio-reactivity of the nanoparticle. J Nanobiotechnology. 2013;11:26.

3. Nguyen VH, Lee BJ. Protein corona: a new approach for nanomedicine design.Int J Nanomedicine. 2017;12:31373151 .

4. Ma W, Saccardo A, Roccatano D, Aboagye-Mensah D, Alkaseem M, Jewkes M, et al. Modular assembly of proteins on nanoparticles. Nat Commun. 2018;9:1489.

5. Sheng Y, Chang L, Kuang T, Hu J. PEG/heparin-decorated lipid-polymer hybrid nanoparticles for long-circulating drug delivery. RSC Adv. 2016;6:23279-23287.

6. Cedervall T, Lynch I, Foy M, Berggård T, Donnelly SC, Cagney G, et al. Detailed identification of plasma proteins adsorbed on copolymer nanoparticles. AngewChemInt EdEngl. 2007; 46:5754-5756.

7. Shannahan JH, Lai X, Ke PC, Podila R, Brown JM, Witzmann FA. Silver nanoparticle protein corona composition in cell culture media. PLoS One. 2013;8:e74001.

8. Schäffler M, Semmler-Behnke M, Sarioglu H, Takenaka $\mathrm{S}$, Wenk A, Schleh C, et al. Serum protein identification 
and quantification of the corona of 5,15 and $80 \mathrm{~nm}$ gold nanoparticles. Nanotechnology. 2013;24:265103.

9. Gessner A, Lieske A, Paulke BR, Müller RH. Functional groups on polystyrene model nanoparticles: influence on protein adsorption. J Biomed Mater Res A. 2003;65:319326.

10. Treuel L, Brandholt S, Maffre P, Wiegele S, Shang L, Nienhaus GU. Impact of protein modification on the protein corona on nanoparticles and nanoparticle-cell interactions. ACS Nano. 2014;8:503-513.

11. Desmet C, Valsesia A, Oddo A, Ceccone G, Spampinato $\mathrm{V}$, Rossi F, et al. Characterisation of nanomaterial hydrophobicity using engineered surfaces. J Nanopart Res. 2017; 19:117.

12. Yu Q, Zhao L, Guo C, Yan B, Su G. Regulating Protein Corona Formation and Dynamic Protein Exchange by Controlling Nanoparticle Hydrophobicity.Front BioengBiotechnol. 2020;8:210.

13. Latour RA. Biomaterials: protein-surface interactions. Encyclopedia of biomaterials and biomedical engineering. 2005;1:270-84.

14. Carrstensen H, Müller RH, Müller BW. Particle size, surface hydrophobicity and interaction with serum of parenteral fat emulsions and model drug carriers as parameters related to RES uptake. ClinNutr. 1992;11:289-297.

15. Aggarwal P, Hall JB, McLeland CB, Dobrovolskaia MA, McNeil SE. Nanoparticle interaction with plasma proteins as it relates to particle biodistribution, biocompatibility and therapeutic efficacy. Adv. Drug Deliv. Rev. 2009;61:428437.

16. D'souza AA, Shegokar R. Polyethylene glycol (PEG): a versatile polymer for pharmaceutical applications. Expert Opin Drug Deliv. 2016;13:1257-1275.

17. Kolate A, Baradia D, Patil S, Vhora I, Kore G, Misra A. PEG - a versatile conjugating ligand for drugs and drug delivery systems. J Control Release. 2014;192:67-81.

18. Lin B, Zhou S. Poly(ethylene glycol)-grafted silica nanoparticles for highly hydrophilic acrylic-based polyurethane coatings. Prog Org Coat. 2017;106:145-154.

19. Rampado R, Crotti S, Caliceti P, Pucciarelli S, Agostini M. Recent Advances in Understanding the Protein Corona of Nanoparticles and in the Formulation of "Stealthy" Nanomaterials.Front BioengBiotechnol. 2020;8:166.

20. Capriotti AL, Caracciolo G, Cavaliere C, Colapicchioni V, Piovesana S, Pozzi D, et al. Analytical methods for characterizing the nanoparticle-protein corona. Chromatographia. 2014;77:755-769.

21. Bohnert T, Gan LS. Plasma protein binding: from discovery to development. J Pharm Sci. 2013;102:2953-2994.

22. Simula MP, Cannizzaro R, Marin MD, Pavan A, Toffoli G, Canzonieri V, et al. Two-dimensional gel proteome reference map of human small intestine. Proteome Sci. 2009;7:10.

23. Rabilloud T, Chevallet M, Luche S, Lelong C. Twodimensional gel electrophoresis in proteomics: Past, present and future. J Proteomics. 2010;73:2064-2077.

24. Tiede K, Hassellöv M, Breitbarth E, Chaudhry Q, Boxall
AB. Considerations for environmental fate and ecotoxicity testing to support environmental risk assessments for engineered nanoparticles. J Chromatogr A. 2009;1216:503509.

25. Nowack B, Bucheli TD. Occurrence, behavior and effects of nanoparticles in the environment. Environ Pollut. 2007; 150:5-22.

26. Monopoli MP, Åberg C, Salvati A, Dawson KA. Biomolecular coronas provide the biological identity of nanosized materials. Nat Nanotechnol. 2012;7:779-786.

27. Walkey CD, Olsen JB, Song F, Liu R, Guo H, Olsen DW, et al. Protein corona fingerprinting predicts the cellular interaction of gold and silver nanoparticles. ACS Nano. 2014;8:2439-2455.

28. Zanella F, Lorens JB, Link W. High content screening: seeing is believing. Trends Biotechnol. 2010;28:237-245.

29. Al-Ali H, Blackmore M, Bixby JL, Lemmon VP. High content screening with primary neurons. InAssay Guidance Manual [Internet]. Eli Lilly \& Company and the National Center for Advancing Translational Sciences. 2014;7-42

30. Roach P, Farrar D, Perry CC. Interpretation of protein adsorption: surface-induced conformational changes. J Am Chem Soc. 2005;127:8168-8173.

31. Langhans SA. Three-dimensional in vitro cell culture models in drug discovery and drug repositioning. Front Pharmacol. 2018;9:6.

32. Lee J, Lilly GD, Doty RC, Podsiadlo P, Kotov NA. In vitro toxicity testing of nanoparticles in 3D cell culture. Small. 2009;5:1213-1221.

33. Lancaster MA, Renner M, Martin CA, Wenzel D, Bicknell LS, Hurles ME, et al. Cerebral organoids model human brain development and microcephaly. Nature. 2013;501:373-379.

34. Kasper J, Hermanns MI, Bantz C, Maskos M, Stauber R, Pohl C, et al. Inflammatory and cytotoxic responses of an alveolar-capillary coculture model to silica nanoparticles: comparison with conventional monocultures. Part FibreToxicol. 2011;8:6.

35. Lehmann AD, Daum N, Bur M, Lehr CM, Gehr P, RothenRutishauser BM. An in vitro triple cell co-culture model with primary cells mimicking the human alveolar epithelial barrier. Eur J Pharm Biopharm. 2011;77:398-406.

36. Huh D, Matthews BD, Mammoto A, Montoya-Zavala M, Hsin HY, Ingber DE. Reconstituting organ-level lung functions on a chip. Science. 2010;328:1662-1668.

37. Bhise NS, Ribas J, Manoharan V, Zhang YS, Polini A, et al. Organ-on-a-chip platforms for studying drug delivery systems. J Control Release. 2014;190:82-93.

38. Ferdous Z, Nemmar A. Health Impact of Silver Nanoparticles: A Review of the Biodistribution and Toxicity Following Various Routes of Exposure. Int J Mol Sci. 2020;21:2375.

39. Nguyen TA, Yin TI, Reyes D, Urban GA. Microfluidic chip with integrated electrical cell-impedance sensing for monitoring single cancer cell migration in three-dimensional matrixes. Anal Chem. 2013;85:11068-11076.

40. Szymański P, Markowicz M, Mikiciuk-Olasik E. Adaptation of high-throughput screening in drug discovery-toxicological 
screening tests. Int J Mol Sci. 2012;13:427-452.

41. Kreuter J. Nanoparticulate systems for brain delivery of drugs. Adv Drug Deliv Rev. 2001;47:65-81.

42. De Jong WH, Borm PJ. Drug delivery and nanoparticles: applications and hazards. Int J Nanomedicine. 2008;3:133149.

43. Alyautdin RN, Tezikov EB, Ramge P, Kharkevich DA, Begley DJ, Kreuter J. Significant entry of tubocurarine into the brain of rats by adsorption to polysorbate 80-coated polybutylcyanoacrylate nanoparticles: an in situ brain perfusion study. J Microencapsul. 1998;15:67-74.

44. Cagliani R, Gatto F, Bardi G. Protein adsorption: A feasible method for nanoparticle functionalization? Materials(Basel). 2019;12:1991.

45. Tavano R, Gabrielli L, Lubian E, Fedeli C, Visentin S, Polverino De Laureto $\mathrm{P}$, et al. C1q-mediated complement activation and $\mathrm{C} 3$ opsonization trigger recognition of stealth poly(2-methyl-2-oxazoline)-coated silica nanoparticles by human phagocytes. ACS Nano. 2018;12:5834-5847.

46. Berrecoso G, Crecente-Campo J, Alonso MJ. Unveiling the pitfalls of the protein corona of polymeric drug nanocarriers. Drug DelivTransl Res. 2020;10:730-750.

47. Chen D, Ganesh S, Wang W, Amiji M. Protein CoronaEnabled Systemic Delivery and Targeting of Nanoparticles. AAPS J. 2020;22:83.

48. Lima T, Bernfur K, Vilanova M, Cedervall T. Understanding the Lipid and Protein Corona Formation on Different Sized Polymeric Nanoparticles. Sci Rep. 2020;10:1129.

49. Shi J, Kantoff PW, Wooster R, Farokhzad OC. Cancer nanomedicine: progress, challenges and opportunities. Nat Rev Cancer. 2017;17:20-37.

50. Treuel L, Docter D, Maskos M, Stauber RH. Protein corona - from molecular adsorption to physiological complexity. Beilstein J Nanotechnol. 2015;6:857-873.

51. Nagayama S, OgawaraK, Fukuoka Y, Higaki K, Kimura T. Time-dependent changes in opsonin amount associated on nanoparticles alter their hepatic uptake characteristics. Int J Pharm. 2007;342:215-221.

52. Tenzer S, Docter D, Kuharev J, Musyanovych A, Fetz V, Hecht R, et al. Rapid formation of plasma protein corona critically affects nanoparticle pathophysiology. Nat Nanotechnol. 2013;8:772-781.

53. Ding T, Sun J. Formation of Protein Corona on Nanoparticle Affects Different Complement Activation Pathways Mediated by C1q. Pharm Res. 2019;37:10.

54. Singh RK, Knowles JC, Kim HW. Advances in nanoparticle development for improved therapeutics delivery: nanoscale topographical aspect. J Tissue Eng. 2019;10:2041731419877528.

55. Satzer P, Svec F, Sekot G, Jungbauer A. Protein adsorption onto nanoparticles induces conformational changes: Particle size dependency, kinetics, and mechanisms. Eng Life Sci. 2016;16:238-246.

56. Wangoo N, Suri CR, Shekhawat G. Interaction of gold nanoparticles with protein: a spectroscopic study to monitor protein conformational changes. Applied Physics Letters. 2008;92:133104.doi: 10.1063/1.2902302.

57. Liu S, Sui Y, Guo K, Yin Z, Gao X. Spectroscopic study on the interaction of pristine $\mathrm{C} 60$ and serum albumins in solution. Nanoscale Res Lett. 2012;7:433.

58. Mahmoudi M, Shokrgozar MA, Sardari S, Moghadam MK, Vali $\mathrm{H}$, Laurent $\mathrm{S}$, et al. Irreversible changes in protein conformation due to interaction with superparamagnetic iron oxide nanoparticles. Nanoscale. 2011;3:1127-1138.

59. Deng ZJ, Liang M, Monteiro M, Toth I, Minchin RF. Nanoparticle-induced unfolding of fibrinogen promotes Mac1 receptor activation and inflammation. Nat Nanotechnol. 2011;6:39-44.

60. Auría-Soro C, Nesma T, Juanes-Velasco P, Landeira-Viñuela A, Fidalgo-Gomez H, Acebes-Fernandez V, et al. Interactions of nanoparticles and biosystems: microenvironment of nanoparticles and biomolecules in nanomedicine. Nanomaterials(Basel). 2019;9:1365.

61. Ge C, Du J, Zhao L, Wang L, Liu Y, Li D,et al. Binding of blood proteins to carbon nanotubes reduces cytotoxicity. Proc Natl Acad Sci USA. 2011;108:16968-16973.

62. Docter D, Westmeier D, Markiewicz M, Stolte S, Knauer SK, Stauber RH. The nanoparticle biomolecule corona: lessons learned - challenge accepted? Chem Soc Rev. 2015;44:60946121.

63. Wang G, Papasani MR, Cheguru P, Hrdlicka PJ, Hill RA. Gold-peptide nanoconjugate cellular uptake is modulated by serum proteins. Nanomedicine. 2012;8:822-832.

64. Patel PC,Giljohann DA, Daniel WL, Zheng D, Prigodich AE, Mirkin CA. Scavenger receptors mediate cellular uptake of polyvalent oligonucleotide-functionalized gold nanoparticles.Bioconjug Chem. 2010;21:2250-2256.

65. Brun E, Sicard-Roselli C. Could nanoparticle corona characterization help for biological consequence prediction? Cancer Nanotechnol. 2014;5:7.

66. Maiorano G, Sabella S, Sorce B, Brunetti V, Malvindi MA, Cingolani R, et al. Effects of cell culture media on the dynamic formation of protein-nanoparticle complexes and influence on the cellular response. ACS Nano. 2010;4:74817491.

67. Krais A, Wortmann L, Hermanns L, Feliu N, Vahter M, Stucky S, et al. Targeted uptake of folic acid-functionalized iron oxide nanoparticles by ovarian cancer cells in the presence but not in the absence of serum. Nanomedicine. 2014;10:1421-1431.

68. Yan Y, Gause KT, Kamphuis MM, Ang CS, O'Brien-Simpson NM, Lenzo JC, Reynolds EC, et al. Differential roles of the protein corona in the cellular uptake of nanoporous polymer particles by monocyte and macrophage cell lines. ACS Nano. 2013;7:10960-10970.

69. Caracciolo G, Cardarelli F, Pozzi D, Salomone F, Maccari G, Bardi $G$, et al. Selective targeting capability acquired with a protein corona adsorbed on the surface of 1,2-dioleoyl-3trimethylammonium propane/DNA nanoparticles. ACS Appl Mater Interfaces. 2013;5:13171-13179.

70. Gurunathan S, Kim JH. Synthesis, toxicity, biocompatibility, and biomedical applications of graphene and graphenerelated materials. Int J Nanomedicine. 2016;11:1927-1945. 
71. Hu W, Peng C, Lv M, Li X, Zhang Y, Chen N, et al. Protein corona-mediated mitigation of cytotoxicity of graphene oxide. ACS Nano. 2011;5:3693-3700.

72. Doorley GW, Payne CK. Nanoparticles act as protein carriers during cellular internalization. ChemCommun(Camb). 2012;48:2961-2963.

73. Manke A, Wang L, Rojanasakul Y. Mechanisms of nanoparticle-induced oxidative stress and toxicity. Biomed Res Int. 2013;2013:942916.

74. Speshock JL, Braydich-Stolle LK, Szymanski ER, Hussain SM. Silver and Gold Nanoparticles Alter CathepsinActivity In vitro. Nanoscale Res Lett. 2011;6:17.

75. Kah JC, Chen J, Zubieta A, Hamad-Schifferli K. Exploiting the protein corona around gold nanorods for loading and triggered release. ACS Nano. 2012;6:6730-6740.

76. Mirshafiee V, Mahmoudi M, Lou K, Cheng J, Kraft ML. Protein corona significantly reduces active targeting yield. Chem Commun (Camb). 2013;49:2557-2559.

77. Salvati A, PitekAS, Monopoli MP, Prapainop K, Bombelli FB, Hristov DR, et al. Transferrin-functionalized nanoparticles lose their targeting capabilities when a biomolecule corona adsorbs on the surface. Nat Nanotechnol. 2013;8:137-143.

78. Dai Q, Walkey C, Chan WC. Polyethylene glycol backfilling mitigates the negative impact of the protein corona on nanoparticle cell targeting. Angew Chem Int Ed Engl. 2014;53:5093-5096. 